\title{
Posture and theophylline kinetics
}

\author{
J. B. WARREN, F. CUSS \& P. J. BARNES \\ Department of Medicine, Respiratory Division, Royal Postgraduate Medical School, Hammersmith Hospital, \\ London, UK
}

The effect of posture on theophylline kinetics was examined in six healthy men who took $450 \mathrm{mg}$ slow-release aminophylline orally at the same time of day on two separate occasions. On one day they remained standing and on the other supine throughout. Plasma theophylline was measured hourly for $6 \mathrm{~h}$ from ingestion. Mean theophylline levels were significantly higher in the standing position at all times $(P<0.01)$. We conclude that diurnal variation in theophylline kinetics can be explained, at least in part, by differences in posture.

Keywords theophylline posture circadian rhythms

\section{Introduction}

Although a valuable drug, the usefulness of theophylline has been limited by a high incidence of side effects. It has recently been suggested that a higher dose of theophylline given at night is not only effective in treating nocturnal asthma but also causes few side effects (Barnes et al., 1982). A possible reason for increased patient tolerance could be the slower rise in theophylline plasma levels when the drug is given at night rather than in the morning (Kyle et al., 1980; Lesko et al., 1980; Scott et al., 1981; Isles et al., 1981; Primrose, 1983; Taylor et al., 1984). Since there is no significant diurnal variation in theophylline metabolism or excretion, it has been suggested that this diurnal difference arises from altered absorption (Taylor et al., 1983).

The short term kinetics of intravenous theophylline are affected by posture, with a substantially higher peak occurring in the upright position (Warren et al., 1983). Therefore, a change in posture could be a simple explanation of the circadian variation in theophylline pharmacokinetics. For this reason we studied the effects of posture on the pharmacokinetics of a commonly prescribed oral slow-release preparation in normal subjects.

\section{Methods}

Six healthy men, who gave informed consent, were studied on two separate occasions. They were hospital personnel aged $25-33$ years with a mean height of $1.82 \mathrm{~m}$ (range 1.72-1.96) and a mean weight of $75 \mathrm{~kg}$ (range 69-79). All were non-smokers and on no regular medication. The study was approved by the hospital ethical committee.

On one occasion they lay supine throughout the experiment and after a $15 \mathrm{~min}$ rest, heart rate and blood pressure were measured. A catheter was inserted in a forearm vein for blood sampling and they then took $450 \mathrm{mg}$ of slow release aminophylline (two tablets of Phyllocontin, Napp Laboratories, Cambridge). Venous blood was sampled at $60 \mathrm{~min}$ intervals after tablet ingestion for a total of $6 \mathrm{~h}$. Heart rate and blood pressure were recorded before each sample.

On another occasion the same experiment was repeated with the subject standing throughout. They were allowed to walk around the laboratory but stood stationary for $5 \mathrm{~min}$ before each set of readings. Each subject started both experiments at the same time of day and all studies started between $07.00 \mathrm{~h}$ and $09.30 \mathrm{~h}$. The lying and standing experiments were performed in random order at least 5 days apart. The subjects 
fasted from the previous evening and were allowed breakfast and lunch after the $1 \mathrm{~h}$ and $4 \mathrm{~h}$ sample respectively. The food and drink taken on the two separate days were identical for each subject.

After sampling, blood was placed in a heparinized tube and plasma separated by centrifugation. Samples were stored at $-70^{\circ} \mathrm{C}$ until assayed by a fluorescent polarization immuno-assay (Abbott TDX) method, which has a coefficient of variation of $<3 \%$. Blood pressure was measured by sphygmomanometer.

\section{Results}

No subject experienced any side effects although all measured theophylline levels were below $8 \mathrm{mg} / \mathrm{l}$.

The peak concentration of theophylline with the subjects standing occurred at $5 \mathrm{~h}$ and was 6.4 $\mathrm{mg} / \mathrm{l}$ (Figure 1). The peak level measured during the lying experiment occurred at $6 \mathrm{~h}$ and was 5.4 $\mathrm{mg} / \mathrm{l}$, although this may have risen further after the end of the experiment. Theophylline concentrations were significantly higher in the standing experiment $(P<0.01$, analysis of variance).

Table 1 shows that theophylline had little effect on blood pressure or heart rate.

\section{Discussion}

Following the initial description of a circadian variation in theophylline toxicity in animals (Kyle et al., 1979), several studies have confirmed a diurnal variation in theophylline pharmacokinetics in humans (Kyle et al., 1980; Lesko et al., 1980; Scott et al., 1980; Isles et al., 1981; Primrose, 1983; Taylor et al., 1980). When the drug is given at night, plasma concentrations of theophylline are characteristically lower over the first $6 \mathrm{~h}$ when compared with daytime dosing, although after this time the curves cross over. However, total absorption as measured by the area under the whole curve, is similar. The most

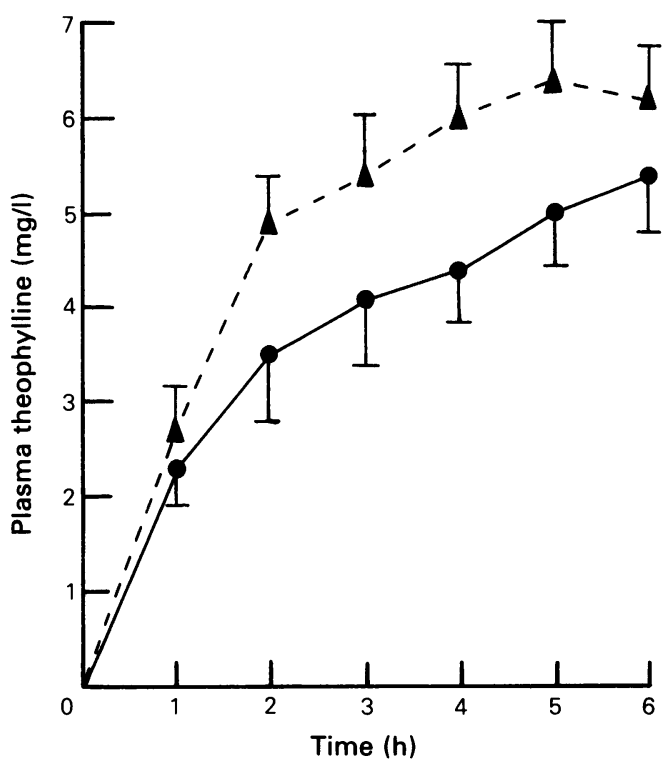

Figure 1 Effect of posture on theophylline pharmacokinetics. Each point is the mean ( \pm s.e. mean) for six subjects. $\triangle--\Delta$ standing, $\bullet-\bullet$ supine.

tenable explanation is that absorption is delayed at night, particularly since theophylline metabolism and excretion show no diurnal variation (Taylor et al., 1983).

When theophylline is given intravenously the effect is far greater if the recipient is standing rather than lying (Warren et al., 1983). In part this is caused by higher peak plasma levels in the upright position. One reason for the difference is a $12-15 \%$ reduction in plasma volume on standing (Thompson et al., 1928), the smaller initial volume of distribution in the standing position causing a higher plasma theophylline concentration. This initial difference disappears as the drug diffuses into the extravascular space. It is possible that these differences in plasma volume may also affect the kinetics of theophylline as it is absorbed from a slow release preparation in the gut. An alternative explanation of the current findings is that the upright posture delays gastric

Table 1 Effect of theophylline on mean ( \pm s.e. mean) heart rate and blood pressure

\begin{tabular}{llrrrrrrr}
\hline & & \multicolumn{1}{c}{ Base } & \multicolumn{1}{c}{$1 \boldsymbol{c} h$} & \multicolumn{1}{c}{$2 h$} & $3 h$ & $4 h$ & $5 h$ & $6 h$ \\
\hline Heart rate & Lying & $63 \pm 4$ & $57 \pm 4$ & $62 \pm 4$ & $61 \pm 5$ & $59 \pm 4$ & $63 \pm 4$ & $62 \pm 4$ \\
(beats/min) & Standing & $74 \pm 3$ & $70 \pm 4$ & $76 \pm 4$ & $78 \pm 6$ & $82 \pm 6$ & $81 \pm 5$ & $83 \pm 8$ \\
Systolic BP & Lying & $112 \pm 3$ & $110 \pm 5$ & $107 \pm 3$ & $110 \pm 5$ & $117 \pm 4$ & $111 \pm 3$ & $110 \pm 4$ \\
(mm Hg) & Standing & $110 \pm 6$ & $103 \pm 2$ & $106 \pm 4$ & $108 \pm 3$ & $110 \pm 4$ & $105 \pm 4$ & $103 \pm 3$ \\
Diastolic BP & Lying & $81 \pm 4$ & $78 \pm 4$ & $78 \pm 3$ & $81 \pm 2$ & $82 \pm 2$ & $76 \pm 2$ & $77 \pm 4$ \\
(mm Hg) & Standing & $81 \pm 5$ & $80 \pm 2$ & $76 \pm 4$ & $78 \pm 4$ & $79 \pm 4$ & $78 \pm 2$ & $76 \pm 3$ \\
\hline
\end{tabular}


emptying and therefore the rate of theophylline absorption from the small bowel. It would have been interesting to extend the experiment beyond $6 \mathrm{~h}$ but the volunteers found standing beyond this time too tiring.

None of the subjects studied reached therapeutic theophylline levels within $6 \mathrm{~h}$ of ingestion despite taking the normally recommended dose of slow-release aminophylline. This highlights the need for adequate dosing in clinical practice.

In the present experiment oral slow release aminophylline produced a more rapid rise in theophylline levels in the upright position. The difference between the absorption curves is very similar to the difference seen between day and night-time dosing. Therefore, it seems that the supine position during sleep may be an adequate explanation for this diurnal variation.

We thank the Chemical Pathology Department, Ealing Hospital, for assaying the theophylline samples, the volunteers who took part, and Napp Laboratories for financial support.

\section{References}

Barnes, P. J., Greening, A. P., Neville, L., Timmers, J. \& Poole, G. W. (1982). Single-dose slow release aminophylline at night prevents nocturnal asthma. Lancet, i, 299-301.

Isles, A. F., Scott, P. \& Tabachnik, E. (1981). Circadian variation in theophylline disposition in asthmatic children. In Drug metabolism in the immature human, eds Soyka, L. F. \& Redmond, G. P., pp. 241-247. New York: Raven Press.

Kyle, G. M., Smolensky, M. H. \& McGovern, J. P. (1979). Circadian variation in the susceptibility of rodents to the toxic effects of theophylline. In Chronopharmacology Proceedings, eds Reinberg, A. \& Halberg, F., pp. 239-244. New York: Pergamon Press.

Kyle, G. M., Smolensky, M. H., Thorne, L. G., Hsi, B. P., Robinson, A. \& McGovern, J. P. (1980). Circadian rhythm in the pharmacokinetics of orally administered theophylline. In Recent Advances in the Chronobiology of Allergy and Immunology, pp. 95-111. Oxford: Pergamon Press.

Lesko, L. J., Brousseau, D., Canada, A. T. \& Eastwood, G. (1980). Temporal variations in trough serum theophylline concentrations at steady state. J. pharm. Sci., 69, 358-359.

Primrose, W. R. (1983). Asthma at night. Lancet, i, 927.

Scott, P. H., Tabachnik, E., McLeod, S., Correia, J., Newth, C. \& Levison, H. (1981). Evidence for circadian variation of theophylline pharmacokinetics. J. Pediatrics, 99, 476-479.

Taylor, D. R., Duffin, D., Kinney, C. D. \& McDevitt, D. G. (1983). Investigation of diurnal changes in the disposition of theophylline. Br. J. clin. Pharmac., 16, 413-416.

Taylor, D. R., Duffin, D., Kinney, C. D. \& McDevitt, D. G. (1984). Circadian variation in plasma theophylline concentrations during maintenance therapy with a sustained-release preparation in patients with obstructive airways disease. $B r . J$. clin. Pharmac., 18, 27-30.

Thompson, W. O., Thompson, P. K. \& Dailey, M. E. (1928). The effect of posture on the composition and volume of blood in man. J. clin. Invest., 5, 573604.

Warren, J. B., Turner, C., Dalton, N., Thomson, A., Cochrane, G. M. \& Clark, T. J. H. (1983). The effect of posture on the sympathoadrenal response to theophylline infusion. Br. J. clin. Pharmac., 16, 405-412.

(Received October 31, 1984, accepted January 14, 1985) 